\title{
VALIDATION AND APPLICATION OF A SIMPLE MODEL FOR CIRCULAR SECONDARY SETTLING TANKS
}

\author{
A.I. STAMOU ${ }^{1}$ \\ D.L. GIOKAS ${ }^{2}$ \\ Y. KIM ${ }^{3}$ \\ P.A. PARASKEVAS ${ }^{4}$
}

Received: 04/04/07

Accepted: 02/10/07

\author{
${ }^{1}$ School of Civil Engineering, Laboratory of Applied \\ Hydraulics, National Technical University of Athens \\ Iroon Polytechniou 5, 15780 Athens, Greece \\ ${ }^{2}$ Department of Chemistry \\ University of Ioannina, Ioannina, 45110, Greece \\ ${ }^{3}$ Dept. of Environmental Engineering \\ Hanseo University, Chungnam 356706, South Korea \\ ${ }^{4}$ Department of Environmental Studies \\ University of the Aegean, Mytilini, 81100, Greece
}

*to whom all correspondence should be addressed: e-mail: stamou@central.ntua.gr

\begin{abstract}
A simple model is presented for the dynamic calculation of the sludge blanket height and concentrations of suspended solids (diluted, sludge blanket and return sludge) in circular secondary settling tanks. The model combines a mass balance equation with three empirical equations, which account for the main processes. These equations form a non-linear, dynamic system, which cannot be solved explicitly; thus, a trial-and-error method is adopted. Field data were obtained from a full-scale treatment plant in transient and steady state conditions and were used in the calibration, the verification and the application of the model. Model calibration involved the determination of only two coefficients, which were found to be relatively constant in various operating conditions. Model verification and application were successful showing a satisfactory agreement with field data. A discrepancy of the model to over-predict sludge blanket height during sudden hydraulic overloads was noted and explained.
\end{abstract}

KEYWORDS: circular secondary settling tasks; diluted sludge concentration; dynamic simulation; non-linear mathematical modelling; sludge blanket; steady-state analysis.

\section{INTRODUCTION}

Biomass sedimentation in Secondary Settling Tanks (SSTs) plays a very important role in the operation of Sewage Treatment Plants (STPS). It contributes to (a) sewage clarification, (b) biomass thickening, and (c) storage of sludge in transient hydraulic or mass overloads thus, protecting the operation from failure. All functions of a SST are related to the dynamic behaviour of the sludge blanket. Sludge blanket is a compaction or sediment layer consisting of Suspended Solids (SS), in the form of sludge flocs, reaching the bottom of the SST and expanding upwards from the bottom of the SST. The height of the sludge blanket $\left(\mathrm{H}_{\mathrm{sb}}\right)$ is probably the most difficult parameter to estimate and one of the most important parameters for the design and operation of SSTs. Without reliable prediction of the sludge blanket height neither maximum SST loading nor appropriate design of SST configuration and equipment are possible. To date, many SSTs usually operate far from the optimum design and operating conditions. This is due to the fact that the height of the sludge blanket depends on several parameters, such as overflow rate, OR (Metcalf and Eddy, 1991), sludge settling characteristics; e.g. settling velocity $\left(\mathrm{V}_{\mathrm{s}}\right)$ and Sludge Volume Index, SVI (Dupont and Dahl, 1995), influent MLSS concentration $X_{i}$ (Joannis et al., 1999), recirculation ratio (r), scraper velocity (Koch et al., 1999), which are difficult to calculate and control simultaneously. 
Due to the importance of the sludge blanket height, a significant number of mathematical models has been developed aiming at the simulation of SSTs, including the dynamic behavior of $\mathrm{H}_{\mathrm{sb}}$. The complexity of these models ranges from simple models, which treat a SST as an ideal settling tank to sophisticated 2-D or 3-D CFD (Computational Fluid Dynamics) models, which include the simulation of the hydrodynamics of SSTs (Krebs, 1995). One-dimensional models have found wide acceptance in the simulation of SSTs, because they can be easily calibrated with simple settling tests and plant measurements. CFD models have attracted the interest of many researchers (see for example Lyn et al., 1992), because they provide a good insight into the processes of hydrodynamics and sedimentation, as well as improved calibration due to the fundamental basis of their structure. However, despite their validity and sound basis, CFD models have not been used extensively in the design and operation of SSTs, because they are generally considered to be too sophisticated to be directly applied in real SSTs, especially in dynamic conditions (Stamou et al., 2000; Stamou, 2006). It is expected, that in the next 10-15 years CFD models will be used in the design and operation of SSTs (Stamou, 2003) but until then, simple empirical models can be applied. The majority of the existing empirical models minimize the number of variables that need to be calibrated and alleviate the need for dynamic data, which are rarely available. The main drawback of such models is the assumption of steady-state conditions, which inherently neglects the dynamics of the SS transfer from the inlet to the compression zone in the bottom of the SSTs. This results in inadequate calibration and consequently in insufficient design, which may cause the operation to fail, especially at dynamic conditions with hydraulic or mass overloads (Giokas et al., 2002a). Therefore, the application of an empirical model in the design of SSTs requires its testing and validation in transient conditions.

The present study deals with the presentation, calibration and application of such a model. The proposed model combines theoretical and empirical equations to calculate (a) the sludge blanket height and (b) the SS concentrations (diluted, sludge blanket and return sludge) in full-scale circular SSTs. Field data were obtained from DELCORA (USA) STP to be used for the calibration and verification of the model.

\section{MODEL DEVELOPMENT}

\subsection{The modeling concept}

In Figure 1 a schematic representation of a SST is shown, which consists of the following 4 zones: (1) clarification, (2) dilution, (3) thickening and (4) compression. In these zones, the following SS concentrations are defined: (1) Inlet concentration, $X_{i},(2)$ effluent concentration, $X_{e}$, (3) diluted concentration, $X_{f},(4)$ sludge blanket concentration, $X_{s b}$, and (5) return sludge concentration, $X_{r}$. Similarly, the following flow rates are defined: (1) Inlet, $Q_{i}$, (2) outlet, $Q_{e},(3)$ return sludge, $Q_{r}$, and (4) surplus (waste) sludge, $Q_{w}$.

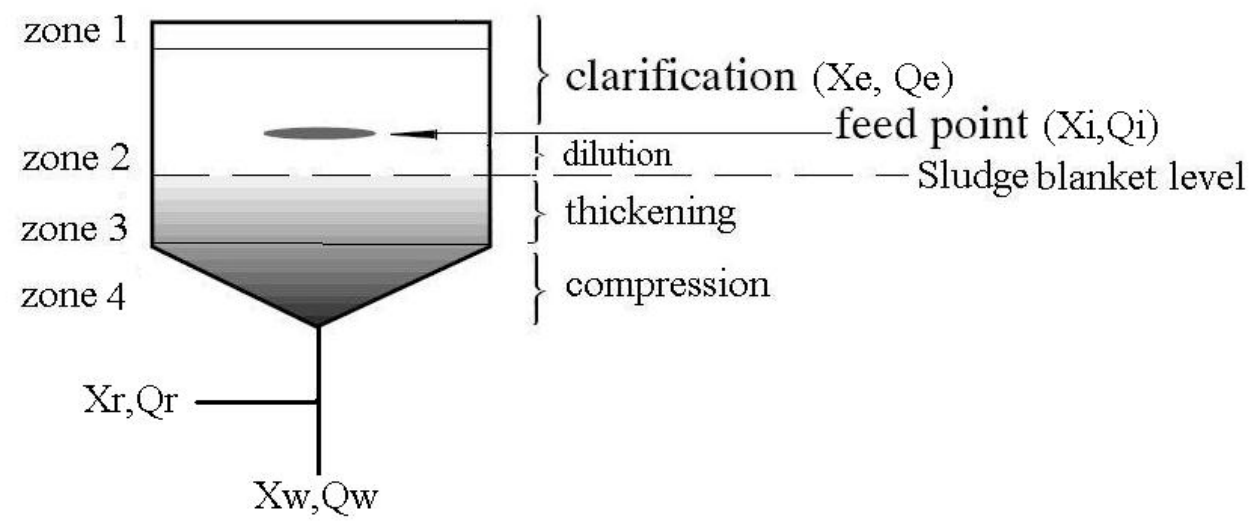

Figure 1. Schematic representation of the zones in a SST

Figure 2 depicts the distribution of SS concentration profiles in a SST determined during three independent sampling trips from the DELCORA plant. Figure 2 verifies the fact that settling of activated sludge in SSTs is a four-stage process involving (1) clarification of the effluent, (2) initial dilution of the inlet concentration, (3) thickening -formation of sludge blanket and (4) 
compression in the lower part of the SSTs. Upon entrance to the SSTs the SS are diluted mainly due to hydrodynamic processes (Joannis et al., 1999). This results in lower concentration of sludge $\left(\mathrm{X}_{\mathrm{f}}\right)$ in the uppermost layer above the sludge blanket than the value of SS, which is measured in the exit of aeration tanks or the inlet of SSTs, $X_{i}$, (Joannis et al., 1999; Giokas et al., 2002b). In the sludge blanket the SS concentration increases gradually from sludge blanket concentration to return sludge concentration.

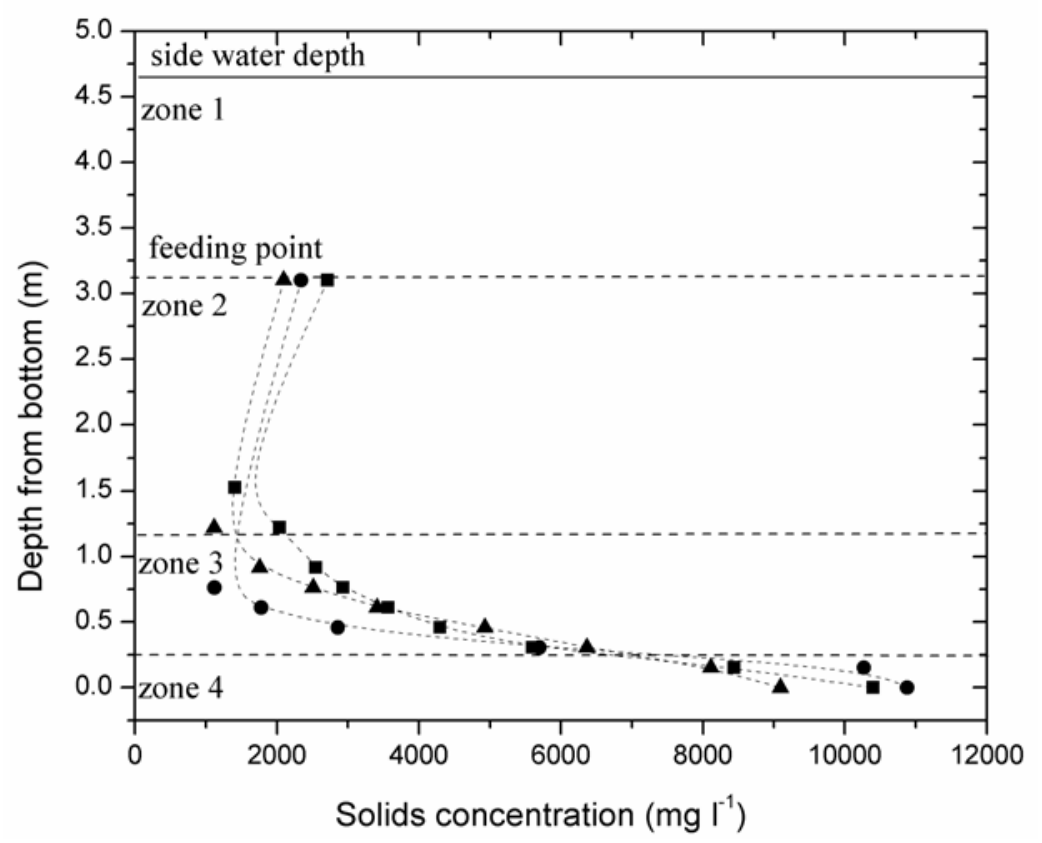

Figure 2. Distribution of SS concentration in a SST

\subsection{Sludge blanket height}

The height of the sludge blanket depends (a) on the geometrical characteristics of the SSTs, (b) the flow characteristics and (c) the SS concentrations in the SSTs; i.e. $X_{f}, X_{s b}$ and $X_{r}$. Theoretically, the height of the sludge blanket, $\mathrm{H}_{\mathrm{sb}}$, can be determined using equation (1).

$\mathrm{M}_{\mathrm{sb}}=\mathrm{X}_{\mathrm{sb}} \times \mathrm{V}_{\mathrm{sb}}=\mathrm{X}_{\mathrm{sb}} \times \mathrm{A} \times \mathrm{H}_{\mathrm{sb}}$

where $M_{s b}$ is the mass of SS in the sludge blanket $(\mathrm{kg}), X_{s b}$ is the average concentration of SS in the sludge blanket $\left(\mathrm{kg} \mathrm{m}^{-3}\right), V_{\mathrm{sb}}$ is the volume of the sludge blanket $\left(\mathrm{m}^{3}\right)$ and $A$ is the surface area of the SST $\left(\mathrm{m}^{2}\right)$.

The dynamic calculation of $H_{s b}$ requires the dynamic calculation of $M_{s b}$. This calculation is performed using the mass balance for the SS in the SSTs

$\frac{\mathrm{dM}_{\mathrm{s}}}{\mathrm{dt}}=\left(\mathrm{Q}_{\mathrm{i}}+\mathrm{Q}_{\mathrm{r}}\right) \mathrm{X}_{\mathrm{i}}-\left(\mathrm{Q}_{\mathrm{r}}+\mathrm{Q}_{\mathrm{w}}\right) \mathrm{X}_{\mathrm{r}}-\left(\mathrm{Q}_{\mathrm{i}}-\mathrm{Q}_{\mathrm{w}}\right) \mathrm{X}_{\mathrm{e}}$

where $M_{s}$ is the mass of SS in the SSTs $(\mathrm{kg})$ and $t$ is the time $(\mathrm{d})$.

Usually, the masses of $S S$ in the effluent and the wastage flows are ignored, i.e. $M_{s}=M_{s b}$, because $Q_{w}<Q_{,}, Q_{w}<Q_{r}, X_{e}<<X_{i}$ and $X_{e}<<X_{r}$; thus, $X_{e}$ and $Q_{w}$ are not involved in the modeling procedure. With these simplifications, equation (2) takes the following form

$\frac{\mathrm{dM}_{\mathrm{sb}}}{\mathrm{dt}}=\left(\mathrm{Q}_{\mathrm{i}}+\mathrm{Q}_{\mathrm{r}}\right) \mathrm{X}_{\mathrm{i}}-\mathrm{Q}_{\mathrm{r}} \times \mathrm{X}_{\mathrm{r}}$

Three more equations will be formulated on the basis of empirical and theoretical concepts to calculate $\mathrm{X}_{\mathrm{r}}, \mathrm{X}_{\mathrm{f}}$ and $\mathrm{X}_{\mathrm{sb}}$.

\subsection{Characteristic times}

In SSTs two characteristic theoretical times are defined: (a) the hydraulic detention time, $\odot$ and $(b)$ the thickening time, $\Theta_{\text {th }}$. 


$$
\begin{aligned}
& \Theta=\frac{\text { volume of wastewater in the SSTs }\left(\mathrm{m}^{3}\right)}{\text { effluent flow rate }\left(\mathrm{m}^{3} \mathrm{~d}^{-1}\right)}=\frac{V}{Q_{e}} \approx \frac{V}{Q_{i}} \\
& \Theta_{\text {th }}=\frac{\text { mass of wastewater in the SSTs }(\mathrm{kg})}{\text { rate of mass of } X \text { leaving the SSTs }\left(\mathrm{kg} \mathrm{d}^{-1}\right)} \approx \frac{M_{s}}{Q_{r} \times X_{r}} \approx \frac{M_{s b}}{Q_{r} \times X_{r}}
\end{aligned}
$$

where $V$ is the volume of the SSTs $\left(\mathrm{m}^{3}\right)$.

\subsection{Return sludge concentration, $X_{r}$}

In steady state conditions, which are commonly adopted in the design of SSTs, equation (3) can take the form of equation (6) (Metcalf and Eddy,1991):

$$
\left(Q_{i}+Q_{r}\right) X_{i}=Q_{r} \times X_{r} \quad X_{r}=\frac{Q_{r}+Q_{i}}{Q_{r}} X_{i} \quad X_{r}=\frac{1+r}{r} X_{i}
$$

However, in dynamic conditions $X_{r}$ is usually calculated by equations describing the process of activated sludge thickening. For this scope, a modified version of the simple model of Roche et al., (1995) is used. The original model of Roche et al., (1995) is written as follows:

$\mathrm{X}_{\mathrm{r}}=\mathrm{a}(\Theta+\Delta \Theta)^{\mathrm{b}}$

$\Delta \Theta$, $a$ and $\mathrm{b}$ and coefficients, which have the following forms

$$
\begin{aligned}
& \mathrm{a}=2.065 \times \mathrm{X}_{\mathrm{i}}^{0.385} \\
& \mathrm{~b}=0.545 \times \mathrm{SVI}^{-0.152} \\
& \Delta \Theta=0.086 \times \mathrm{X}_{t}^{2.234}
\end{aligned}
$$

where SVI is the Sludge Volume Index $(\mathrm{ml} / \mathrm{l}) . \Delta \Theta$ (d) accounts for the compression time advancement of the activated sludge.

Pipes and Kim (1996) proposed two modifications in equation (7). Firstly, they argued that $\Delta \Theta$ is small compared to $\Theta$ and has almost no effect on the calculated value of $X_{r}$; thus, it can be omitted. Secondly, they questioned the use of $\Theta$ and proposed its substitution by the thickening time $\Theta_{\text {th }}$. By adopting these modifications, equation (7) can be combined with equation (5) to result in equation (11).

$$
X_{r}=\left[a\left(\frac{M_{s b}}{Q_{r}}\right)^{b}\right]^{\frac{1}{b+1}}=\left[a\left(\frac{X_{s b} \times A \times H_{s b}}{Q_{r}}\right)^{b}\right]^{\frac{1}{b+1}}
$$

\subsection{Diluted concentration, $X_{f}$}

The diluted SS concentration, $X_{f}$, influences the sludge blanket height. To demonstrate this effect, two series of real-time data were obtained from the DELCORA plant: (a) Steady state and (b) $155 \mathrm{~h}$ consecutive dynamic data. These data, which are plotted in Figure 3, show the 3 regions of SST: (1) overloaded $\left(X_{i} / X_{f} \leq 1.5\right)$, (2) normal loaded $\left(1.5 \leq X_{i} / X_{f} \leq 3.0\right)$ and (3) under loaded $\left(X_{i} / X_{f} \geq 3.0\right)$. In Figure 3 the critical value of $H_{s b}$ is also shown, which is the maximum value of $\mathrm{H}_{\mathrm{sb}}$, above which SS washout occurs; this value was estimated equal to $2.75 \mathrm{~m}$.

Figures $3 a$ and $3 b$ depict that when the ratio $X_{i} / X_{f}$ increases, $H_{s b}$ decreases. A few outlier peaks observed in Figure $3 b$ in the region of $X_{i} / X_{f}>2$ can be attributed either to experimental error or to the relatively slow response to rapid changes in the $X_{i} / X_{f}$ ratio, especially for high $S V I$ values. A more detailed analysis of this behavior is provided in the experimental part

In steady state conditions $X_{f}$ can be determined using the mass balance in the inlet zone (Figure 1), which is written as follows:

$$
\left(Q_{i}+Q_{r}\right) X_{i}=\left(Q_{r}+V_{s} \times A\right) X_{f} \text { or } \quad X_{f}=\frac{Q_{i}+Q_{r}}{Q_{r}+V_{s} \times A} X_{i}=\frac{1+r}{r+V_{s} / O R} X_{i}
$$

where $V_{S}$ is the settling velocity of the $S S\left(m d^{-1}\right), O R=Q_{i} / A$ is the overflow rate $\left(m^{-1}\right)$ and $\mathrm{H}_{\mathrm{a}}=\mathrm{V}_{\mathrm{s}} / \mathrm{OR}$ is the Hazen number (-). 


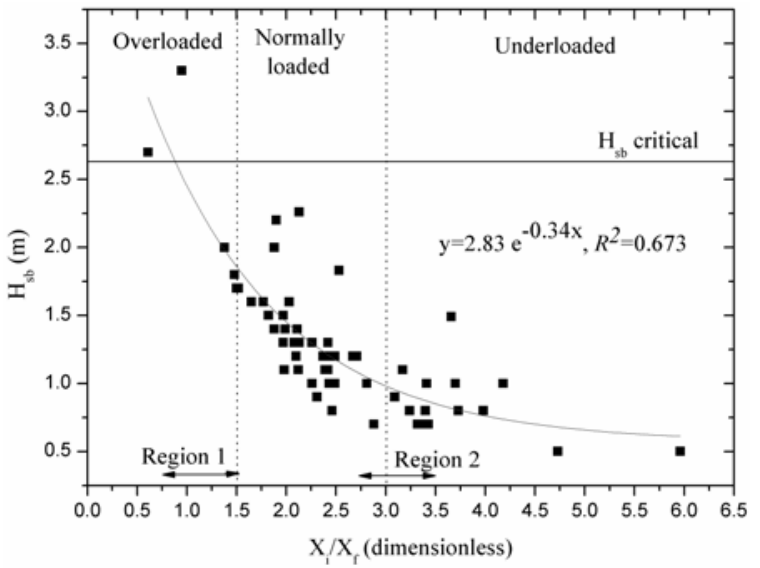

(a)

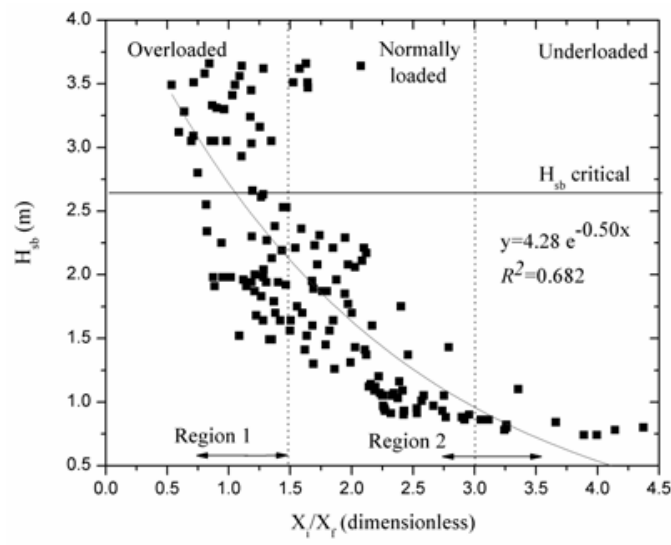

(b)

Figure 3. Variation of $\mathrm{H}_{\mathrm{sb}}$ as a function of the ratio $\mathrm{X}_{\mathrm{i}} / \mathrm{X}_{\mathrm{f}}$.

(a) Steady-state data and (b) Dynamic data

In equation (12) the process of settling is modeled as a flow of the SS in the direction of gravity with velocity $V_{S}$. In simple mathematical models, $V_{S}$ is assumed to be constant. $A$ more realistic approach is to use a Settling Velocity Curve (SVC), in which, the SS are divided into classes, due to the variation of particle diameter, each having a discrete settling velocity (Stamou et al., 1989). In practice, however, it has been found that $V_{S}$ is a function of the local SS concentration $\left(\mathrm{X}_{\mathrm{i}}\right)$. Following this practical concept, which takes into account the hindered settling due to sludge floc aggregation, Takacs et al., (1991) proposed a double exponential function between $V_{S}-X_{i}$, in which, at low values of $X_{i}, V_{S}$ increases with $X_{i}$ until a value of $X_{i}$, at which $V_{S}$ attains a maximum value and then starts to drop with a further increase of $X_{i}$. Alternatively, the integrated approach proposed by Giokas et al., (2003) can be used for the determination of $V_{s}$, as a function of SVI. The application of these approaches in the initial formulation of the model showed, that for typical values of $Q_{r}$ and $X_{i}, X_{f}$ was significantly overestimated (always $X_{f}>X_{i}$ ), with the exception of very large values of $Q_{r}$, at which $X_{f}$ approximates $X_{i}$. This means that a simple steady-state mass balance equation, such as equation (12), is not capable to calculate the diluted activated sludge concentration $\left(X_{f}\right)$.

To overcome this difficulty a simpler approach was adopted, which is based on equation (11) and the assumption that the time the SS spent from the upper part of sludge blanket to the withdrawal point is equal to the time diluted sludge spent from the surface of the SST to the bottom. This approach results in equation (13); see Giokas et al. (2002b).

$X_{f}=\frac{Q_{r} \times X_{r}^{b+1 / b}}{a^{1 / b} \times A \times H}$

\subsection{Sludge blanket concentration, $X_{s b}$}

For the calculation of $X_{s b}$ the theoretical approach of Halttunen (1996) was used, which describes the rate of thickening by equation (14).

$\frac{\partial \mathrm{X}}{\partial \mathrm{t}}=\frac{1}{\mathrm{k}_{1} \mathrm{X}}$

where $k_{1}$ is a thickening factor $\left(g^{-2} m^{-6} d^{2}\right)$ incorporating the effects of all the properties of activated sludge, such as floc density, size, shape etc. Integrating equation (14) from initial time $(t=0)$ to thickening time $\left(\Theta_{\mathrm{th}}\right)$ and from the initial concentration, $\mathrm{X}_{\mathrm{sb}}$ (in the sludge blanket) to final concentration (in the bottom of SSTs) $X_{r}$, results in equation (15).

$\Theta_{\mathrm{th}}=0.5 \times \mathrm{k}_{1} \times\left(\mathrm{X}_{\mathrm{sb}}^{2}-\mathrm{X}_{\mathrm{r}}^{2}\right)$

Moreover, a modified version of the model of Nielsen et al. (1996), which is based on the concept of Sludge Volume Loading, reads as follows

$\mathrm{V}=\mathrm{k}_{2} \times \mathrm{Q}_{\mathrm{i}} \times \mathrm{X}_{\mathrm{sb}} \times \mathrm{SVI}$

where $k_{2}$ is a coefficient $\left(\mathrm{m}^{3} \mathrm{~d} \mathrm{~kg}^{-1}\right)$. 
Combining equations (5), (15) and (16), and using the experimental data of the present work, equation (17) is derived.

$$
X_{s b}=\frac{X_{r}}{\sqrt{1+\frac{H_{s b}}{H} \times \frac{Q}{Q_{r}} \times \frac{S V I}{X_{r}}}}
$$

\subsection{Formulation of the finite differential equations}

Integration of equation (3) over the volume of the SST using forward time differences between $\mathrm{n}$ and $\mathrm{n}+1$ time levels, or times $\mathrm{t}$ and $\mathrm{t}+\mathrm{dt}$, where the values of any variable, $\mathrm{X}$, are denoted by $X^{n}$ and $X^{n+1}$, respectively, yields:

$$
\frac{\left(M_{s b}\right)^{n+1}-\left(M_{s b}\right)^{n}}{\Delta t}=\left(Q_{i}^{n}+Q_{r}^{n}\right) \times X_{i}^{n}-Q_{r}^{n} \times X_{r}^{n}
$$

Inserting equation (1) into (18) the latter is written as follows:

$$
X_{s b}^{n+1} \times H_{s b}^{n+1}=X_{s b}^{n} \times H_{s b}^{n}+\frac{\Delta t}{A} \times\left[\left(Q_{i}^{n}+Q_{r}^{n}\right) \times X_{i}^{n}-Q_{r}^{n} \times X_{r}^{n}\right]
$$

Equations (11), (13), (17) and (19) are the four basic equations of the model forming a nonlinear, dynamic system of simple equations, which cannot be solved explicitly. Therefore, the trial-and-error method of solution was adopted.

\section{EXPERIMENTAL}

\subsection{Materials and methods}

Experimental data were obtained from the Western Regional Treatment Plant located in Chester, Pennsylvania (DELCORA, Delaware County Regional Water Quality Control Authority) USA (Kim, 1995). This STP was rated to treat an average of $Q_{i}=166540 \mathrm{~m}^{3} \mathrm{~d}^{-1}$, but frequently had difficulties in handling hydraulic overloads during rainstorm periods $\left(Q_{i}>170000\right.$ $\mathrm{m}^{3} \mathrm{~d}^{-1}$ ). The activated sludge process consists of (a) four mechanically aerated biological reactors with a total volume equal to $37850 \mathrm{~m}^{3}$ and (b) four circular, up-flow center feed SSTs with a total area of $4930 \mathrm{~m}^{2}$ and side water depth equal to $4.57 \mathrm{~m}$. The maximum capacity of the return sludge pumps is $90840 \mathrm{~m}^{3} \mathrm{~d}^{-1}$.

Three sets of data were obtained from the DELCORA plant: S1, S2 and S3. S1 consists of average daily dynamic data for one year. S2 contains dynamic data during 155 consecutive hours of operation, including days with rainstorm events that caused hydraulic overloads. S3 consists of steady-state data collected during 58 sampling trips to the plant. Steady-state operation was assumed to occur when the criterion of non-variable amount of sludge solids stored in the SSTs was satisfied. In addition, two more sets of data consisting of average and dynamic data from other researchers (Watts et al., 1996; Manning et al.,1999) were used to demonstrate the general applicability of the proposed model.

The plant operators measured $Q_{i}, Q_{r}$ and $H_{s b}$ and effluent turbidity (practically $X_{e}$ ) in the four SSTs every two hours; $X_{i}$ and $X_{r}$ were measured every twelve hours. Suspended solids determinations were performed in duplicate in each sample following Method 213C of the Standard Methods for the Examination of Water and Wastewater (APHA, 1995). The samples to determine the sludge blanket height were obtained with an integrated sludge sampler (sludge judge) composed of a transparent sampling tube, a check valve and a support rod (Kim and Pipes, 1996 and 1999; Kim et al.,1997). The transparent tube permitted the visual determination of the interface between water and sludge; $\mathrm{H}_{\mathrm{sb}}$ was calculated by subtracting the height of the side water depth and then the average value of $\mathrm{H}_{\mathrm{sb}}$ for the four SSTs was determined.

The sludge settling properties (initial settling velocity) and the SVI were measured with a 1 I graduated cylinder (diameter $6 \mathrm{~cm}$, height $0.345 \mathrm{~m}$, settling time for SVI determination $30 \mathrm{~min}$ ), which was stirred at $1 \mathrm{rpm}$ to minimize wall effects. Four sets of settling tests were performed for each of the mixed liquor samples and the results were averaged. The SVI observed in this study corresponds to the SSVI (stirred SVI) and was occasionally lower than the SVI values obtained by the operators at the plant, where the sludge was not stirred. 


\subsection{Processing of data}

The calibration of the model involved the minimization of the sum of squared errors between model calculations and measurements ( $\mathrm{R}^{2}$ or $\mathrm{R}$ - Coefficient or Index of Determination). This method shows the proportion of the variance of the observed data, which is explained by the model, but it does not give adequate information for the absolute or the relative deviation of the calculated values from the actual values, which is also of interest in dynamic simulations. For this purpose, the quality of fit between simulated values and available data was also evaluated by calculating the Average Relative Deviation (ARD) between model predictions and data points using the following expression:

$$
A R D=\frac{1}{n} \sum_{i=1}^{n}\left(\frac{X_{i}^{m}-X_{i}^{c}}{X_{i}^{m}}\right)
$$

where ARD is the average relative deviation, $\mathrm{n}$ is the number of experimental data points, $X_{i}^{m}$ are the measured values and $X_{i}^{c}$ are the calculated values.

\section{RESULTS AND DISCUSSION}

\subsection{Calibration of the model}

The calibration of the model involved the determination of the coefficients a and b. Four data sets were randomly selected and used in the calibration. The following exponential expressions were derived for the determination of the coefficients $a$ and $b$.

$$
\begin{aligned}
& \mathrm{a}=2.180( \pm 0.07) \times \mathrm{X}_{i}^{0.327( \pm 0.03)} \\
& \mathrm{b}=0.525( \pm 0.04) \times \mathrm{SVI}^{-0.143( \pm 0.01)}
\end{aligned}
$$

Equations (21) and (22) are almost identical to equations (8) and (9), respectively, although measurements from various treatment facilities have been used.

\subsection{Verification of the model}

In Figure 4 calculated $X_{f}$ values are compared with measurements. In Figure 5 calculated $X_{r}$ values are compared with measurements (Set S1) and with the calculations of the models of Böhnke and Pöppinghaus (1990) and Roche et al. (1995). Figure 4 shows a satisfactory agreement between calculations and field data. Furthermore, Figure 5 shows that the calculated $X_{r}$ values are in good agreement with the measured values (set S1). The calculated slope (s) and intercept (i) of the best-fit line indicate that the proposed model is better than the other two models; $s=0.88$ and $i=0.28$ for the present model, $s=0.69$ and $i=2.10$ for Böhnke and Pöppinghaus,1990 and s=0.15 and i=3.40 for Roche et al., 1995.

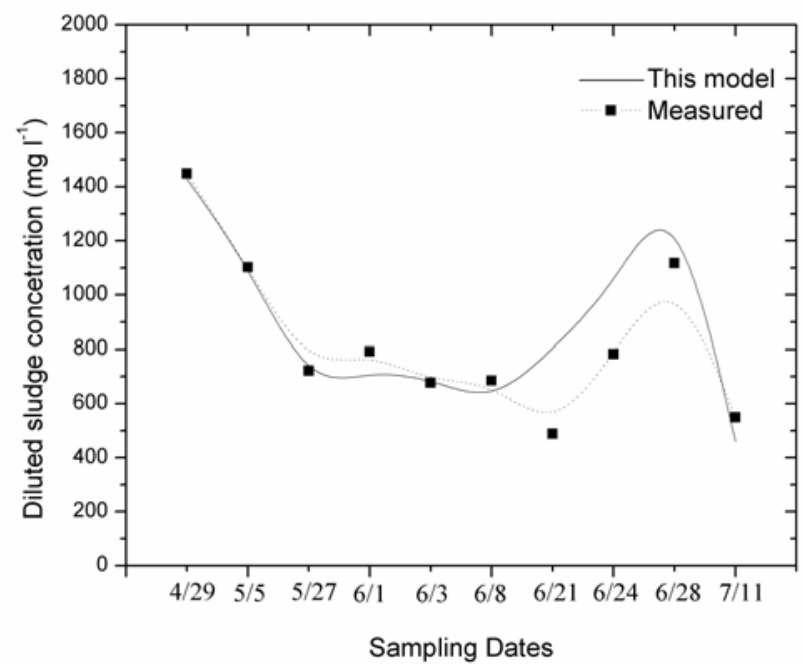

Figure 4. Comparison of calculated values of $\mathrm{X}_{\mathrm{f}}$ with measurements 


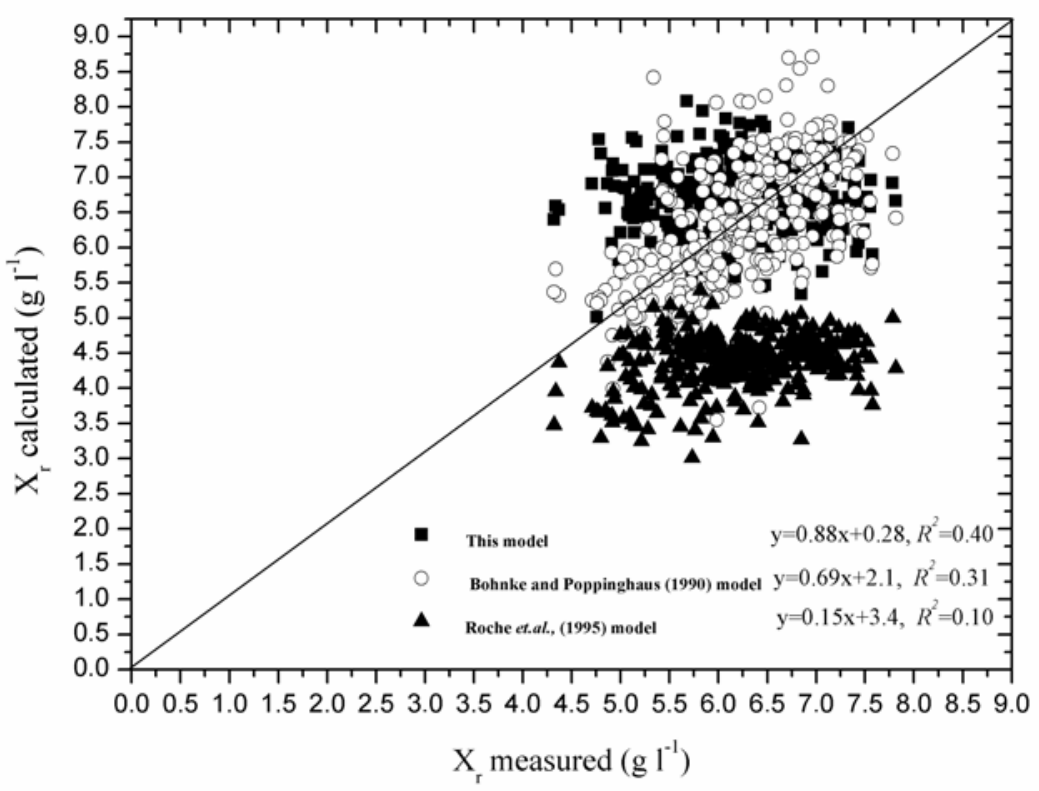

Figure 5. Comparison of calculated values of $X_{r}$ with measurements for the 3 models

In Figure 6a the comparison of calculated versus measured SS concentrations in the sludge blanket (steady-state data - set S3) is depicted. The characteristics of the best-fit line (slope $=0.786$, intercept $=0.541$ ) show that the proposed model offers a good approximation of the real behavior. The simulation using dynamic data (set S2) shown in Figure 6b, is also supportive to this conclusion revealing that the model can also satisfactorily predict the real dynamic behavior of the process.

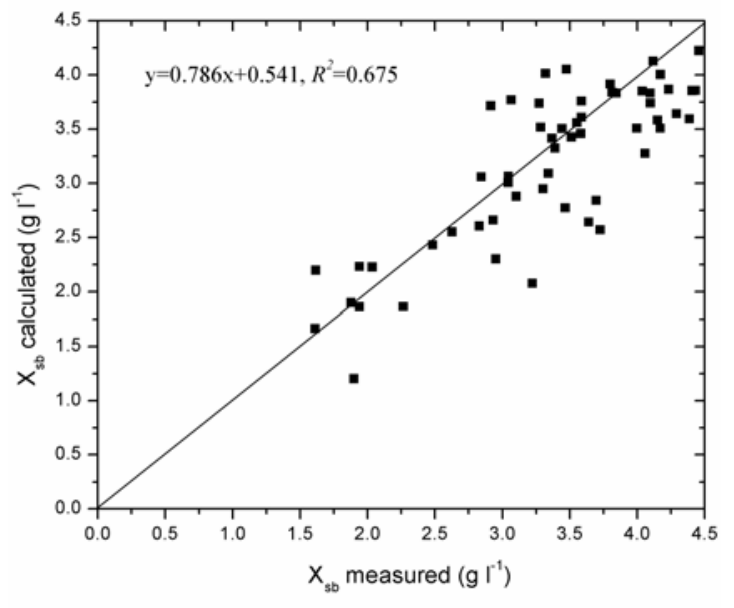

(a)

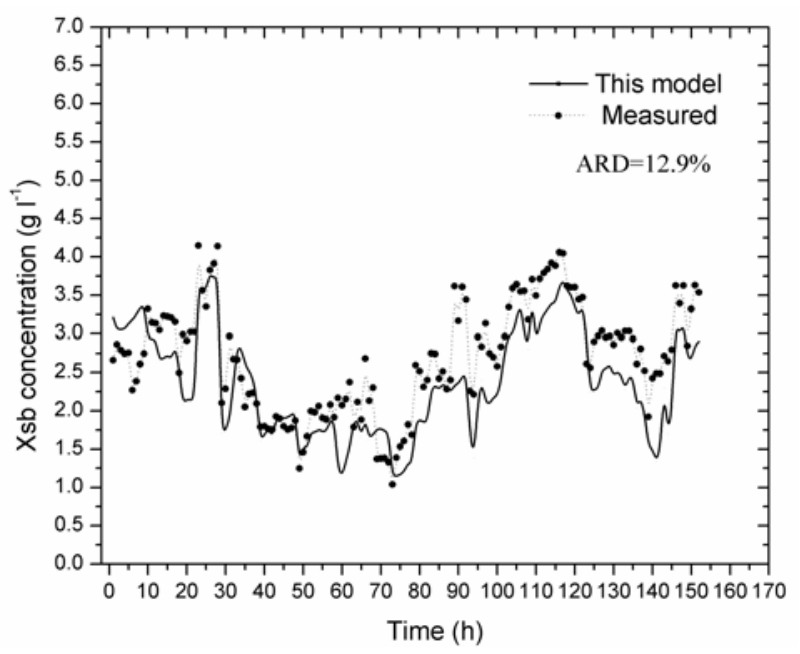

(b)

Figure 6. Comparison of calculated sludge blanket concentrations with (a) steady state data and (b) dynamic data (155 h of continuous operation)

\subsection{Application of the model-Discussion}

The model was applied to calculate the variation of the sludge blanket height for (a) the daily average dynamic data along with the measured values (set S1) and (b) the $155 \mathrm{~h}$ consecutive dynamic data from the DELCORA plant (set S2). These variations are shown in Figure $7 a$ and $b$, respectively, together with field data. 


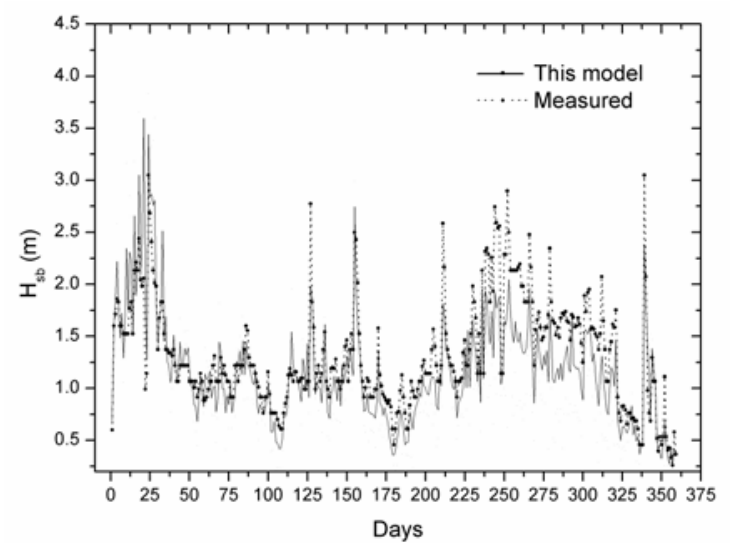

(a)

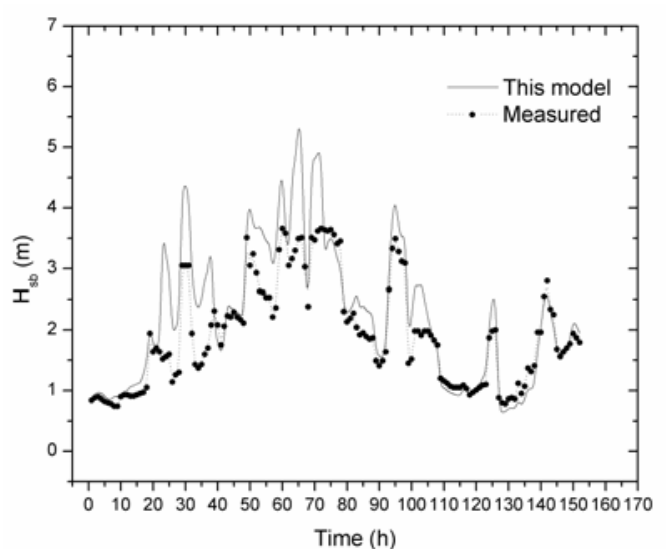

(b)

Figure 7. Comparison of calculated sludge blanket height with (a) 1-year average dynamic data and (b) dynamic data (155 h of continuous operation)

Figure 7 a depicts that the prediction of the sludge blanket is very satisfactory, taking into account the long operational period. The calculated ARD value is also satisfactory, being equal to $23 \%$. However, it is noted that, despite the satisfactory performance of the model, extreme values in sudden transient conditions (storm surges) are generally overestimated. Figure $7 \mathrm{~b}$ also shows a satisfactory simulation of the $\mathrm{H}_{\mathrm{sb}}$ pattern. However, during sudden hydraulic changes, the model tends to over-predict the height of the sludge blanket. From the practical point of view, this conservative behavior can be seen as a positive attribute of the model, because it warns for a coming failure, such as an SS washout. Since $X_{s b}$ is predicted satisfactorily, the overestimation of the $H_{s b}$ in extreme conditions can be attributed to the overestimation of the $X_{f}$ values. This is due to the fact that equation (13), for simplicity reasons, describes the process of dilution on the incoming SS in a very simplified way, as a function of the return sludge concentration and the incoming flow rate (Joannis et al., 1999). Therefore, abrupt changes in the operation, such as hydraulic overloads, cannot be modeled adequately. Similar deviations were also reported in the majority of models (Dupont and Dahl, 1995; Göhle et al., 1996; Chatellier and Audic, 1998; Joannis et al., 1999; Manning et al., 1999; Chatellier and Audic, 2000) revealing a general mathematical discrepancy in such conditions. Research is currently in progress to develop a more efficient, but still simple equation, for the calculation of $X_{f}$ involving the hydraulic characteristics of the SST.

Beyond model structure, the quality of input data is very critical for the successful realistic dynamic simulation of SSTs. This is particularly true when dynamic rather than steady state or average dynamic data are used. In the present work, a sampling interval equal to two hours was adopted and proved to be adequate in most occasions. However, this value could not reflect very rapid changes resulting in overestimation of the actual behavior as also evidenced with other models (Göhle et al., 1996; Joannis et al., 1999). This suggests that when the operation becomes critical, time intervals between consecutive samplings should be significantly abridged in order to account for the real behavior. Otherwise, the predictions are liable to reflect the quality of the input data rather than the ability of the model to simulate the process. Unfortunately, such data are rarely available.

The applicability of the model was further assessed with two data sets from the literature; (a) a set of average data from Watts et al. (1996) and (b) a set of data from Manning et al. (1999) obtained during hydraulic overloads induced by storm surges.

The comparison between calculated and measured values of the sludge blanket height, which is shown in Figure 8, demonstrates a satisfactory approximation of the real behavior. The calculation of the temporal variation of the sludge blanket height is also 
satisfactory and consistent to the previous findings; the model tends to overestimate the sludge blanket height in hydraulic overloads.

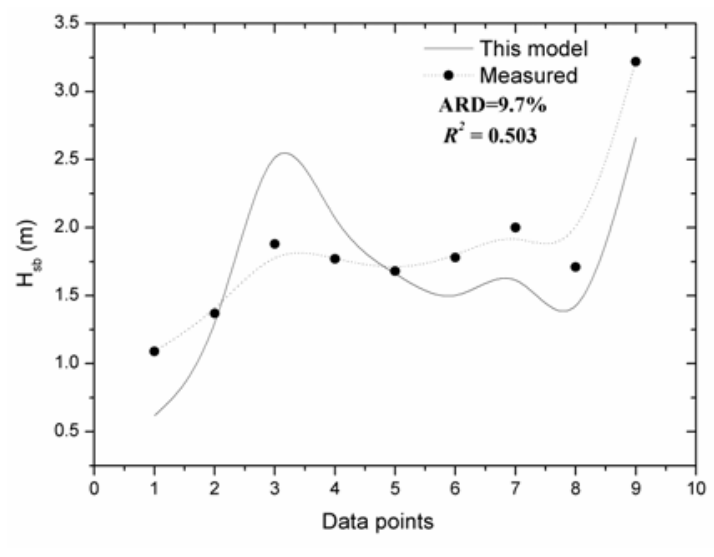

(a)

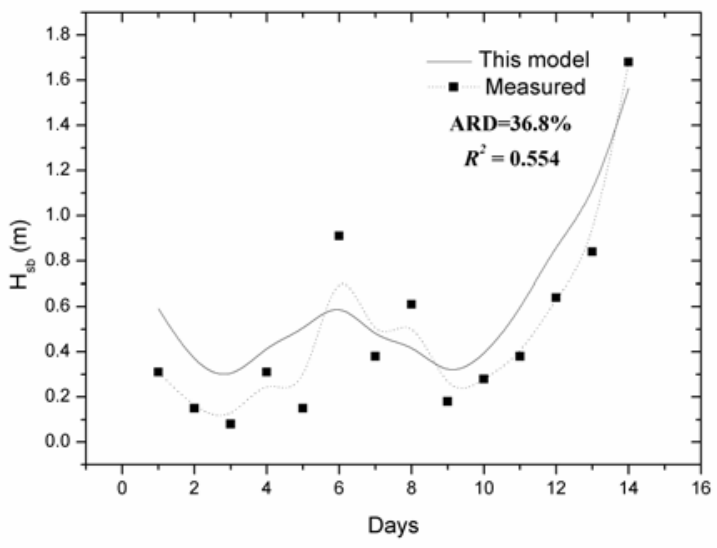

(b)

Figure 8. Comparison of calculated sludge blanket height with the data of

(a) Watts et al. (1996) and (b) Manning et al. (1999)

\section{CONCLUSIONS}

A simple model was formulated using a mass balance equation and three empirical equations, which account for the main processes in SSTs. These equations formed a nonlinear dynamic system with only two coefficients that remain practically unchanged in various operating conditions, and solved numerically by trial-and-error. The verification and application of the model were successful indicating a satisfactory description of the operation of SSTs for various operating conditions ranging in complexity from steady state to dynamic. Calculations showed a satisfactory agreement with field data although the model tended to over-predict the sludge blanket height during sudden hydraulic overloads. By exploiting this conservative behaviour as an early warning system of operational failure, the model can safely be used in the design of SSTs (steady-state analysis).

\section{REFERENCES}

APHA, (1995), Standard methods for the examination of water and wastewater, $18^{\text {th }}$ ed., Washington, D.C.

Böhnke B. and Pöppinghaus K., (1990), Technologie des eaux residuaires. production, pollecte, traitement et analyse des eaux residuaires, Springer-Verlag, Paris, France, 698.

Chatellier P. and Audic J.M., (1998), A new model for wastewater treatment plant clarifier simulation, Water Res., 34(2), 690-693.

Chatellier P. and Audic J.M., (2000), An empirical dynamic model for wastewater treatment plant clarifier simulation, Environ. Technol.,19, 725-731.

Dupont R. and Dahl C., (1995), A one-dimensional model for a secondary settling tank including density current and short-circuiting, Water Sci. Technol., 31(2), 215-224.

Giokas D.L., Vlessidis A.G., Angelidis M.O., Tsimarakis G.J. and Karayannis M.I., (2002a), Systematic analysis of the operational response of activated sludge process to variable wastewater flows. A case study, Clean Technol. Environ. Policy, 4, 183-190.

Giokas D.L., Kim Y, Paraskevas P.A., Paleologos E.K. and Lekkas T.D., (2002b), A simple empirical model for activated sludge thickening in secondary clarifiers, Water Res., 36(13), 3245-3252.

Giokas D.L., Daigger G.T., von Sperling M., Kim, Y. and Paraskevas P.A., (2003), Comparison and evaluation of empirical zone settling velocity parameters based on sludge volume index using a unified settling characteristics database, Water Res., 37(16), 3821-3836.

Göhle F., Finnson A. and Hultman B., (1996), Dynamic simulation of sludge blanket movements in a full-scale rectangular sedimentation basin, Water Sci. Technol., 33(1), 9-16.

Halttunen S., (1996), Thickening in an activated sludge process clarifier, Water Sci. Technol., 33(12), 171-180.

Joannis C., Aumond M., Dauphin S., Ruban G., Deguin A. and Bridoux G., (1999), Modelling activated sludge mass transfer in a treatment plant, Water Sci. Technol., 39(4), 29-36. 
Kim Y., (1995), Solids storage function of activated sludge settling tanks during hydraulic overloads, Ph.D Thesis, Drexel University.

Kim Y. and Pipes W.O., (1996), Solids routing in an activated sludge process during hydraulic overloads, Water Sci. Technol., 34(3-4), 9-16.

Kim Y. and Pipes W.O., (1999), Factors influencing suspended solids concentration in activated sludge settling tanks, J. Haz, Mater., 67, 95-109.

Kim Y., Pipes W.O. and Chung P., (1997), Estimation of suspended solids concentrations in activated sludge settling tanks, Water Sci. Technol., 35(8), 127-135.

Koch G., Pianta R., Krebs P. and Siegrist H., (1999), Potential of denitrification and solids removal in the rectangular clarifier, Water Res., 33(2), 309-318.

Krebs P., (1995), Successes and shortcomings of clarifier modelling, Water Sci. Technol., 31(2), 181-191.

Lyn D.A, Stamou A. and Rodi W., (1992), Density currents and shear induced flocculation in sedimentation tanks, J. Hydraulic Eng., ASCE., 118(6), 849-867.

Manning Jr. W.T., Garrett Jr. M.G. and Malina Jr. J.F., (1999), Sludge blanket response to storm surge in an activated-sludge clarifier, Water Environ. Res., 71, 432-442.

Metcalf and Eddy, (1991), Wastewater Engineering: Treatment, Disposal and Reuse, $3^{\text {rd }}$ ed. McGraw-Hill, New York.

Nielsen M.K., Carstensen J. and Harremoës P., (1996), Combined control of sewer and treatment plant during rainstorm, Water Sci. Technol., 34(3-4), 181-187.

Pipes W.O. and Kim Y., (1996), Discussion of "A simple empirical model for hindered settling in activated sludge clarifier. By Roche, N.; Vaxelaire, J.; Prost, C. Wat. Environ. Res. 1995, 67, 775-.780", Water Environ. Res., 68, 123-125.

Roche N. Vaxelaire J. and Prost C., (1995), A simple empirical model for hindered settling in activated sludge clarifier, Water Environ. Res., 67, 775-780.

Stamou A.I., (2003), Towards a protocol for the validation of CFD models for secondary settling tanks, 30th IAHR Congress, September, 2003, Thessaloniki, Greece.

Stamou A.I., (2006), A design methodology for settling tanks using CFD models, IASME Trans. Fluid Mechanics, 4(1), 304-312.

Stamou A.I., Adams E.W. and Rodi W., (1989), Numerical simulation of flow and settling in primary rectangular clarifiers, J. of IAHR, 27, 665-682.

Stamou A.I., Latsa M. and Assimakopoulos D., (2000), Design of two-storey final settling tanks with mathematical models, J. Hydroinformatics, 2-4, 235-245.

Takacs I., Patry G. and Nolasco D., (1991), Dynamic model of clarifier-thickening process, Water Res., 25(10), 1263-1271.

Water Environment Federation / American Society of Civil Engineers (1999), Design of municipal wastewater treatment plants, No. 76, Vol. 2, $4^{\text {th }}$ ed.

Watts R.W., Svoronos S.A. and Koopman B., (1996), One-dimensional modelling of secondary clarifiers using a concentration and feed velocity-dependent dispersion coefficient, Water Res., 30(9), 2112-2124. 